European Journal of Adapted Physical Activity, 1(2), 7-19

(C) European Federation of Adapted Physical Activity, 2008

\title{
USING PEER-MEDIATED INSTRUCTIONS FOR STUDENTS WITH SEVERE AND MULTIPLE DISABILITIES IN INCLUSIVE PHYSICAL EDUCATION: A MULTIPLE CASE STUDY
}

\author{
Aija Klavina \\ Latvian Academy of Sport Education Medicine and Physical Therapy, Riga, Latvia
}

The purpose of this study was to determine the effect of peer-mediated and teacher - directed instructions on the activity engagement time of students with severe and multiple disabilities (SMD). The data were obtained during inclusive general physical education sessions under two kinds of instructional support conditions for three students with SMD: (a) teacher-directed, and (b) peer-mediated. Instructional behavior data showed that during peer-mediated support conditions the instructions provided by tutors were more frequent than instructions provided by teachers during teacher-directed conditions. Physical behavior data indicated that peer-mediated conditions resulted in similar levels of physical behaviors for all students with SMD when compared to teachersdirected conditions. Also, for all students with SMD the activity engagement time data was higher in conditions where peer tutors were involved.

KEY WORDS: Peer Tutoring, Students with Severe and Multiple Disabilities, Adapted Physical Education.

\section{INTRODUCTION}

Adapted physical education (APE) teachers are encouraged to use effective support strategies when including students with disabilities in physical education classes (DePaepe, 1985; Murata \& Jansma, 1998; Webster, 1987). Students with severe and multiple disabilities (SMD) often require oneto-one instructions in both inclusive and segregated education placements (Block, Conatser, Montgomery, Flynn, Munson, \& Dease, 2001; Block, Klavina, \& Flint, 2007; Vogler, Koranda, \& Romance, 2000). In an inclusive general physical education (GPE) class, there may be one APE teacher and a number of students with disabilities requiring APE service (Kelly \& Gansneder, 1998; Zhang, Kelly, Berkey, Joseph, \& Chen, 2000) of whom some may have SMD. With large numbers of students who have diverse learning potential and physical challenges, teachers are concerned about how to provide each student with an effective instructional accommodation (LaMaster, Gall, Kichin, \& Siedentop, 1998). The APE teacher to student ratio may restrict participation and performance levels not only for students with disabilities as discussed by
Zhang and colleagues, but for all students in the class.

The most common strategies that APE teachers have used to relieve this restriction and provide students with disabilities more individualized instructions is to have peers without disabilities to work with the individual student (DePaepe, 1985; Lieberman et al., 1997, 2000; Webster, 1985). For example, Houston-Wilson, Dunn, van der Mars, and McCubbin (1997) found that peer tutors can benefit motor skills of elementary school age students with moderate disabilities by delivering cues, prompts, feedback and serving as models. Also, the APE research literature have addressed other types of peer involvement in teaching process, for example, combined support by peer tutors and GPE teacher (Murata \& Jansma, 1998). Regardless of the type and level of peer assistance, the goal is to enhance participation of students with disabilities, including those with SMD, in GPE activities. In addition, peer involvement in teaching procedures provides the natural contexts for spontaneous and voluntary behaviors among all students in the setting (Kohler \& Strain, 1999).

However, maintaining continuous and successful relationships between students with 
and without SMD requires more efforts and patience, and might be less fun than relationships with non-disabled peers, or peers with mild and moderate disabilities (Cole, 1988). If no external rewards (e.g., praise, positive feedback by teachers) or internal reinforcement (e.g., positive attitude, good feeling about helping others) are available, the durability and benefit of such relationships is doubtful. This notion is supported by social learning theory (Bandura, 1977) and contact theory (Allport, 1954) indicating that non frequent and superficial interactions between members of different groups will result in decreasing of interaction frequency, and such relationships will disappear over time. Solutions that could potentially improve inclusion of students with SMD in GPE settings considers extending support resources and applying structural conditions that affords equal status relationships and natural, voluntary interactions regardless of whether student has disability, or not.

In the USA, the APE research has shown that peer tutoring strategies have resulted in an increase of academic outcome (Lieberman et al., 1997, 2000). The special education research has indicated that peer mediated support may increase the amount of time devoted for instructions (Greenwood, Dinwiddie, Terry, Wade, Stanley, Thibadeau, \& Delquadri,1984; Kamps, Locke, Delquadri \& Hall, 1989; Martella, Marchand-Martella, Young \& MacFarlane, 1995) Also, Huston-Wilson and colleagues (1997) identified that instructions provided by tutors to students with disabilities increased after peer tutor training. As mentioned before, peer assistance to students with SMD should be done under supervision of a teacher with additional teacher attention and rewards regarding providing instructions, monitoring peer tutor rotation (i.e., $10 \mathrm{~min}$ period for one tutor) so that any of tutors did not get tired and overwhelmd during the tutoring process. To date, no research in APE has looked at and compared peer tutor instructions and teacher instructions when including students with SMD in GPE class.

The preliminary study (Klavina \& Block, 2008) focused on interaction behaviors demonstrated by students with SMD towards their peers without disabilities including peer tutors and students who were not designated tutors. The purpose was to measure the impact of the peer-mediated instructional accommodation on interaction behaviors between students with and without disabilities in GPE class. The findings showed that during teacher-directed instructional conditions (before peer tutoring intervention) students with SMD had more interactions with the teacher (i.e., APE teacher, teacher assistant), while the introduction of peer tutoring resulted in increased interactions between target students and their peer tutors as well as with other classmates. This study examined the effect of peer-mediated and teacher-directed instructions on activity engagement time of students with SMD. Thus, the instructional behavior data provided by the teacher and peer tutors towards students with SMD from preliminary study were reanalyzed to address the purpose of this study. In other words, we were interested whether instructions of peer-tutors or teachers would be similar across teacher-directed and peer-mediated instruct-ional conditions.

\section{METHOD}

The methodological approach followed Klavina and Block (2008).

\section{Participants}

Target Students. Three students with SMD from two elementary schools located in a midAtlantic state in the United States participated in this study. They attended a self-contained classroom which is a special education classroom for students with disabilities where they spend the most of their school day with little to no integration with general education classes. All target students spent about $60 \%$ or more of their school time in the self-contained classroom. Students with SMD were addressed as Eric, Laura and Mary (pseudonyms).

Eric was a 9-year old boy with AtaxiaTelangiectasia, a hereditary degenerative disorder with a severe loss of coordination and balance. Also, he had limited communication skills. During the GPE class Eric often needed 
two persons' assistance to transfer in the gym and participate in activities. Eric was extremely well behaved, and he wanted to be pleased, and accomplish a task. Classmates seemed to like him, although it was challenging for them to do activities together, or to communicate with Eric. His IEP-PE objective was emphasized inclusion in GPE together with peers given continuous physical assistance using adaptive sport equipment and providing modifications in activities. Laura was an 8-year-old girl with severe intellectual disabilities. She also had moderate motor difficulties, poor body awareness, and severe speech difficulties. Her behavior sometimes was disruptive and noncompliant which seemed to be related to attempts to avoid the task. Her current IEP-PE goals included objectives related to ball skills (e.g., rolling, catching, throwing), gross motor skills (e.g., jumping, running), and participation in collaborative activities with peers without disabilities. Mary was a 9-year-old girl with cerebral palsy, severe mental retardation and very limited vocabulary. She needed physical assistance in all activities during GPE class (e.g., following directions, participating in individual tasks, or games). Mary's current IEP-PE objectives included goals related to her participation in GPE activities together with peers given moderate verbal and physical assistance. All students were included in the GPE class for full time (i.e., 90-120 minutes per week).

Peer Tutors. Nine general education students served as peer tutors (four for Eric, two for Laura, and three for Mary). To recruit them, the first researcher talked to all of the general education students participating in GPE class together with target students about peer tutoring study. She then gave all interested students the parents consent form. In addition, the classroom teachers and GPE teachers were asked to recommend tutors whom they thought to be most appropriate based on their opinion on students' skills and abilities to follow the requirements of the peer tutoring program. The final participants were selected from the pool of students who brought signed consent forms, showed interest in participating and could commit their time during the study.
All selected general education students received three, 30-minute training sessions in how to serve as a peer tutor. The student with SMD and his or her teacher assistant attended the second and third session. Because of time constraints, APE teachers partly attended training sessions. However, they were provided all materials used in training sessions and informed about the progress of peer tutor skills. At the beginning of the first session, the researcher and tutors discussed differences in people. The main purpose of this discussion was to teach tutors empathy and compassion so that they would learn to treat their classmates with disabilities the way they would like to be treated. Then, rules and roles of being a peer tutor were discussed (e.g., being friendly, talk softly, and providing praises). The first researcher provided the Peer Tutor Training Manual which included instructions, called TIP-TAP steps (i.e., Tips to Teach, Assist and Practice) on how to provide instructional assistance to the peer with SMD in GPE class. First, tutors were taught to provide cue telling the student with SMD about the activity. For example, the peer tutor told his or her tutee, "We are going to throw the ball." Second, the peer tutor did the first task trial together with the tutee. If the tutee performed the task correctly, then the peer tutor gave positive feedback by saying, "Great job!" or another phrase expressing good effort. If the tutee did not perform task correctly, then the peer tutor provided error correction and prompted the tutee (e.g., "It was good try, but you did not keep your arms in front."). Third, if the tutee still did not follow directions, then the tutor provided correct model. In other words, the tutor demonstrated the task by saying, "Watch me" or "Keep your arms like this." If the tutee required physical assistance, then tutors were instructed by the adult person (i.e., first researcher, teacher assistant, or APE teacher) on how to assist the student with SMD (e.g., how to hold the tutee's arm to help him or her keep balance while rolling the ball). During training as well as during intervention sessions the tutors were reminded to ask for teacher's help if they could not manage inappropriate behavior of the tutee, or faced other problems 
while assisting the peer with SMD. For example, if the teacher noticed that the peer tutor and the tutee were not interacting for 2030 seconds, the teacher approached the students' dyad by asking, "Is everything is OK? Let me know if you need my help."

On the second and third training session tutors and student with SMD were randomly assigned to work in pairs to practice the TIPTAP steps. Selected activities matched the GPE sport unit in particular schools and allowed implementing training practice appropriate to the real GPE class situation. All activities were monitored by the first researcher to ensure that each tutor had an opportunity to practice with the target student. During training as well as during intervention sessions the tutors were reminded to ask for teacher's help if they could not manage inappropriate behavior of the tutee, or faced other problems while assisting the peer with SMD. For example, if the teacher noticed that the peer tutor and the tutee were not interacting for 2030 seconds, the teacher approached the students' dyad by asking, "Is everything OK? Let me know if you need my help."

During the third training session assessment trials were completed for each peer tutor when he or she was paired with the student with SMD. Peer tutors had to reach the 90\% criterion regarding providing teaching instructions for three consecutive trials. To determine the effectiveness of the training program peer tutors were asked to complete the peer tutor evaluation forms. Tutors had to score $100 \%$ in this evaluation.

Staff. Two full-time GPE teachers (male and female) had 26 and 29 years teaching experience, respectively. They were consistent in their teaching style and daily lessons, and they performed willingness including children with disabilities in their GPE classes. The APE teachers in this study were two male teachers with 14 years and 4 years of teaching experience. Both served adapted physical education in several schools across the county. Special education personnel in this study represented teacher assistants providing supports to students with SMD throughout their school day. Their assistance during GPE class differed among target students. For example, Eric received support from both the teacher assistant and the APE teacher at the same time, while Laura and Mary's teacher assistant would leave the setting when the APE specialist assisted them in GPE.

The GPE classes taught by GPE teachers were 45 minutes in length and held twice or three times per week for each class. Class sizes were about 25-30 students. The elementary GPE program followed a model in which sport units were organized in 1-2 weeks blocks. The classes consisted 5-10 minutes of the warm-up period, 15-25 minutes of the main part, and 510 minutes of games at the end of class.

\section{Variables}

The primary dependent variable in this study was instructional behaviors provided by peer tutors and teachers (i.e., APE teacher, and assistant teacher) towards students with SMD. Instructional behaviors - any verbal or nonverbal instructions directed to other(s) in order to complete the objective or task (Klavina, 2007). These measures included cues, prompts, and various types of feedback (general, specific and corrective). As in Klavina and Block (2008), the secondary dependent variable was the active engagement time for students with SMD called physical behaviors. Physical behaviors are active engagement in individual or group activities related to the objective or tasks in GPE when students are learning, or practicing on a physical activity (e.g., playing basketball), or a skill (e.g., dribbling the ball) (Klavina, 2007). In this study the changes in activity engagement scores were analyzed in relation to data illustrating instructions provided by teachers and peer tutors towards students with SMD across study phases.

\section{Data Collection}

In the study by Klavina and Block (2008) data were collected for a total of 46 sessions including (a) 20 minutes of the main part, and (b) 10 minutes of the last part of GPE session. In this study data were analyzed from all observation sessions during the 20 minutes of the main part of GPE class when peer-mediated instructional conditions were implemented. A 
single subject delayed multiple baseline research design across participants was used. All observation sessions were collected on videotapes with the use of the SONY Digital Handycam. The student with SMD wore a wireless microphone to enable the researcher to monitor interaction behaviors.

During teacher-directed (i.e., baseline) conditions APE teachers provided instructions to the student with SMD as before the study. Although, APE teachers occasionally asked random general education students to join the student with SMD in activities, they presented direct instructions and physically assisted target students throughout GPE sessions.

During peer-mediated instructional conditions peer tutors were assigned by the APE teacher to assist the student with SMD. The teacher then stepped back and monitored tutoring activities from about a 3-5 $\mathrm{m}$ distance. Also, he ensured a systematic rotation of peer tutors (10 min period for one tutor) so that none of the tutors would get tired or overwhelmed during the tutoring process. The teacher praised both the peer tutor and the student with SMD on successful partnership and collaboration to help maintain students' confidence and enjoyment during tutoring

\section{Table 1}

\section{List and Definitions of Instructional Codes}

(Cole, 1988; Logan et al., 1998). In addition, ongoing feedback was provided to peer tutors after each GPE class to correct interaction behaviors and improve the ways they provided teaching instructions.

\section{Data Analyzes}

The Computerized Evaluation Protocol of Interactions in Physical Education (CEPI-PE) (Klavina \& Selavo, 2006) was used to code and record instructional behaviors. The CEPI-PE categorical variables have been validated in two pilot studies for its use with elementary school students in GPE setting (Klavina, 2007). In the CEPI-PE instructions are classified in five subcategories: (1) cue, (2) prompt, (3) general feedback, (4) specific feedback, and (5) corrective feedback (Table 1). For example, if the peer tutor provided general feedback to the student with SMD (e.g., "You are doing great today!") then ' $\mathrm{Fg}$ ' was recorded. The fivesecond observation and five-second record partial interval system was applied. This is data recording procedure where an observer is interesting whether a behavior occurs or does not occur in any part of the interval marking occurrence or nonoccurrence of a targeted behavior.

\begin{tabular}{lll}
\hline Definition and (Code) & Sample Definition & \multicolumn{1}{c}{ Example } \\
$\begin{array}{l}\text { Cue Delivery } \\
\text { (C) }\end{array}$ & $\begin{array}{l}\text { Provides verbal or nonverbal } \\
\text { directional cue about GPE, or IEP- } \\
\text { PE directed activity. }\end{array}$ & $\begin{array}{l}\text { Says "We are going to roll the ball", or visually } \\
\text { presents the equipment (shows the ball), or } \\
\text { shows an activity card from the picture board. }\end{array}$ \\
\hline $\begin{array}{l}\text { Prompting } \\
\text { (P) }\end{array}$ & $\begin{array}{l}\text { Provides any type of verbal or } \\
\text { perform the task correctly, or more } \\
\text { efficiently. }\end{array}$ & $\begin{array}{l}\text { Says "Push a ball to me", or "Push like this" } \\
\text { (demonstrates). }\end{array}$ \\
\hline $\begin{array}{l}\text { General feedback } \\
\text { (Fg) }\end{array}$ & $\begin{array}{l}\text { Provides a supportive statement } \\
\text { about the student's performance }\end{array}$ & Says "Good job!" or "You are doing great!" \\
\hline $\begin{array}{l}\text { Specific feedback } \\
\text { (Fs) }\end{array}$ & $\begin{array}{l}\text { Provides a supportive statement } \\
\text { indicating exact information about } \\
\text { what was good about the student's } \\
\text { performance }\end{array}$ & $\begin{array}{l}\text { Says, "I like how you step forward with your } \\
\text { left foot." or "Good try, but you did not step } \\
\text { with the opposite foot when you threw the ball." }\end{array}$ \\
\hline $\begin{array}{l}\text { Corrective feedback } \\
\text { (Fc) }\end{array}$ & $\begin{array}{l}\text { Provides a statement indicating exact } \\
\text { information as to what the student } \\
\text { did not do correctly. Can be also } \\
\text { applied for inappropriate behavior } \\
\text { management. }\end{array}$ & $\begin{array}{l}\text { Says "You did not lift your arms up." } \\
\text { Says "Don't push." or "John, you have to listen } \\
\text { quietly." }\end{array}$ \\
\hline
\end{tabular}


Statistical analyze. The obtained data were analyzed based on raw scores, percentage mean scores and visual inspection of graphs. Wilcoxon Signed-Rank Test examined differences in instructional and physical engagement measures for peer tutors and teachers while assisting students with SMD during baseline and intervention, Wilcoxon-Mann-Whitney U test assessed differences between groups and Spearman Rank Correlation Coefficient examined correlation between instructions and activity engagement time scores for peer tutors and teachers with students with SMD.

\section{Reliability}

Interobserver agreement and procedural reliability data were collected with a trained second observer for an average of $30 \%$ of all observations. The percentage agreement and the Cohen's kappa statistic (Cohen, 1960) were used for the interval level agreement since it corrects for agreement by chance. The mean and range of kappa coefficients and percentage agreements across participants was .80 (.64 $1.00)$ and $90 \%(80 \%-100 \%)$, respectively. The TIP-TAP steps provided in the Peer Tutor
Training Manual were assessed for procedural reliability including following behaviors, (a) presenting cue, (b) presenting verbal prompt, (d) demonstrating, (e) providing appropriate feedback (e.g., specific praise, correcting errors), and (f) providing physical assistance. The procedural reliability agreement was calculated by agreements divided by agreements plus disagreements multiplied by $100 \%$. The agreement score above $80 \%$ was defined acceptable (Kazdin, 1982). The overall mean for accurate use of the TIP-TAP steps was $98 \%$ (range, $95 \%$ to $100 \%$ ).

\section{RESULTS}

\section{Descriptive Data}

Data for each target student are presented as: (a) instructional behaviors by peer tutors and teachers across baseline and intervention sessions (Figure 1), (b) physical behaviors between peer tutors and the target student and between the teacher and the target student (Figure 1), and (c) activity engagement time of students with SMD (Figure 2).

\section{Figure 1}

Mean percentage of intervals during which teachers and peer tutors were involved in instructional and physical interactions with students with SMD
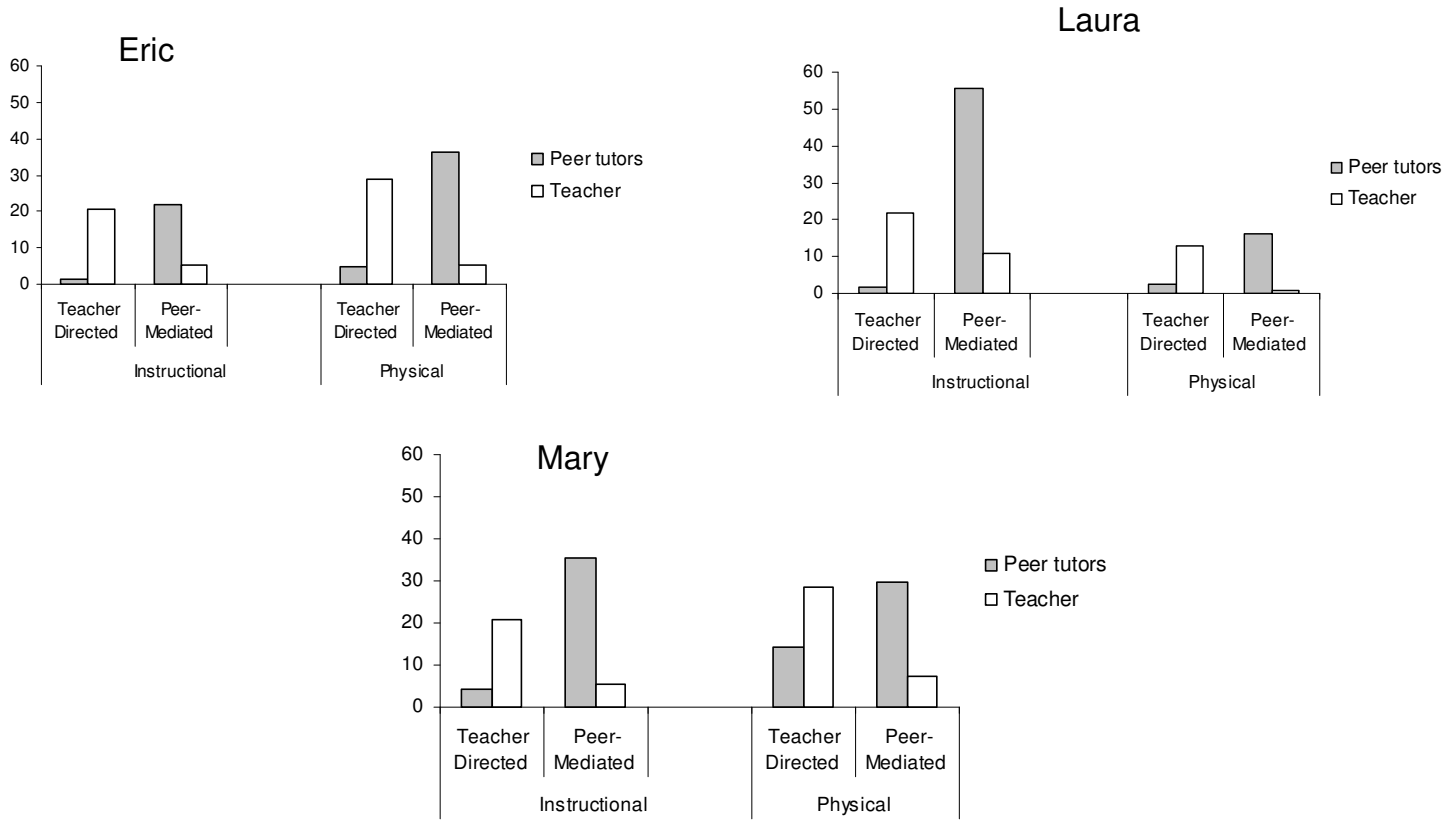
During GPE periods under teacherdirected instructional conditions (i.e., baseline) the percentage mean scores for instructions provided by teachers towards students with SMD ranged from $20.8 \%$ to $21.8 \%$ (Figure 1). In contrast, instructional involvement of selected yet not trained peer tutors was minimal ranging from $1.2 \%$ to $4.4 \%$. Furthermore, physical interaction scores illustrate that teachers' involvement in physical activities with students with SMD ranged from $12.8 \%$ to $28.7 \%$, while physical interactions between tutors and their peers with SMD ranged 1.2\% to $14.4 \%$. As indicated in the Figure 1, Mary's peer tutors had more interactions with her than selected tutors and students with SMD in two other settings. As indicated by Klavina and Block (2008), the variability in physical interaction scores across participants may be attributed to the alternating involvement of general education students in interactions with peers with SMD as directed by the APE teacher in each site. The activity engagement scores during baseline varied across the three target students ranging from $46.2 \%$ to $61.3 \%$ (Figure 2).

\section{Figure 2}

Mean percentage of intervals in activity engagement for students with SMD teacher-directed and peer-mediated conditions
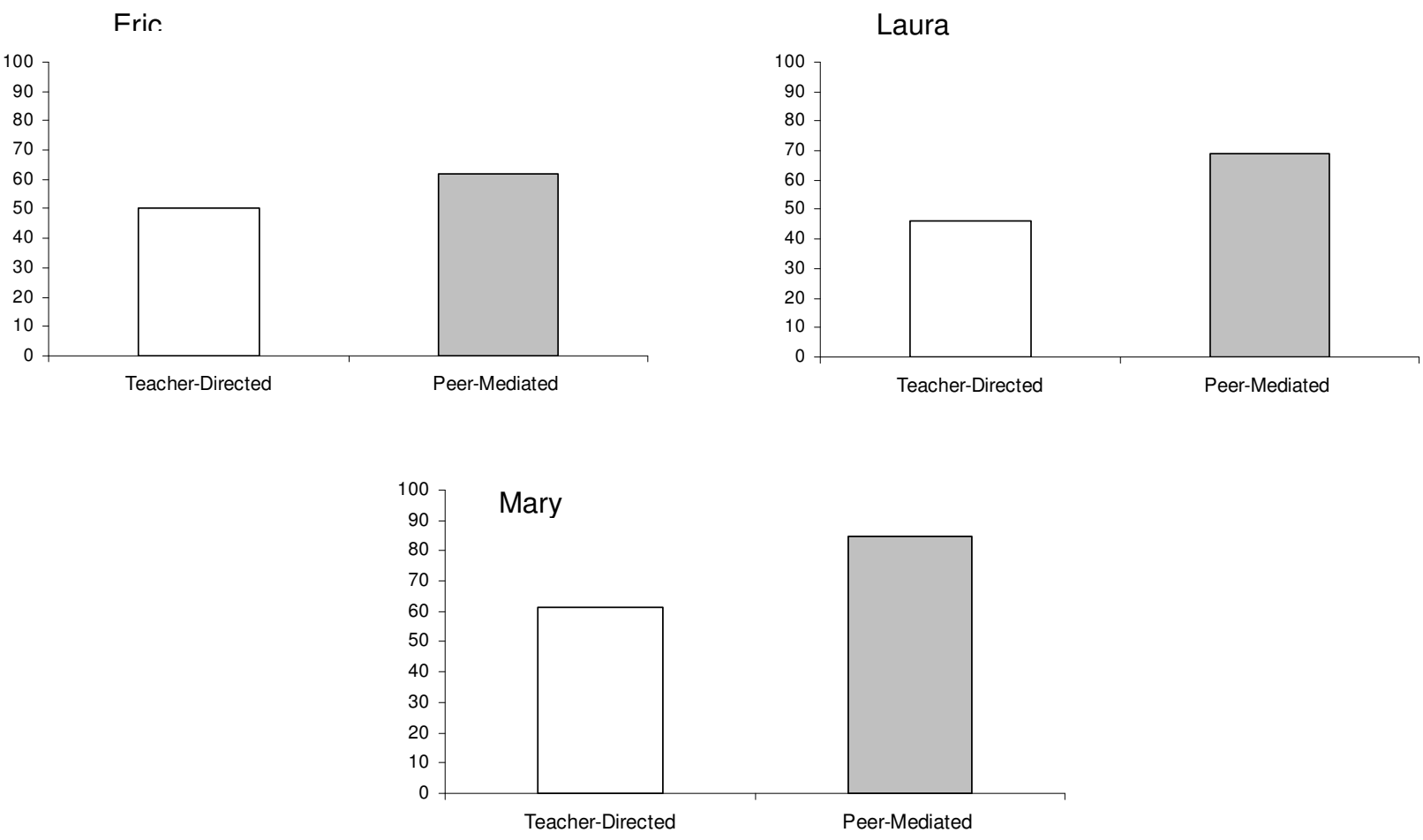

The introduction of peer-mediated instructional conditions resulted in an immediate increase in interaction behaviors between peer tutors and target students. For Laura's peer tutors the mean score of instructional behaviors increased to $55.7 \%$, for Mary's peer tutors this score increased to $35.2 \%$, and for Eric's peer tutors to $21.8 \%$ (Figure 1). The graphed data show that peer tutors provided more instructions during intervention than teachers during the baseline phase. Furthermore, Table 2 shows that peer tutors considerably increased prompt scores. Also, these data show that peer tutors most frequently used general rather specific or corrective feedback. The physical interaction scores demonstrated by peer tutors towards their tutees were variable. The mean score for 
Mary's peer tutors was $29.5 \%$, for Laura's peer tutors $16.0 \%$, and for Eric's peer tutors $36.6 \%$. Although, peer tutors showed higher activity engagement with students with SMD during peer-mediated conditions than teachers during baseline sessions, the visual inspection of graphs of physical interactions showed that teacher and peer tutor scores slightly differ across two research phases (Figure 1, Physical).

Table 2

Mean Percentage of Intervals in Instructional Interaction Behaviors Demonstrated by Peer Tutors across Teacher-Directed and Peer-Mediated Conditions

\begin{tabular}{|c|c|c|c|c|c|c|c|}
\hline $\begin{array}{c}\text { Target } \\
\text { student }\end{array}$ & Phase & $\begin{array}{l}\text { Person(s) } \\
\text { providing } \\
\text { instructions }\end{array}$ & $\mathrm{P}$ & $\mathrm{C}$ & $\mathrm{Fg}$ & Fs & $\mathrm{Fc}$ \\
\hline \multirow{4}{*}{ Eric } & \multirow{2}{*}{$\begin{array}{l}\text { Teacher- } \\
\text { Directed }\end{array}$} & Peer Tutors & .6 & .3 & .3 & .0 & .0 \\
\hline & & APE teacher & 8.3 & 2.5 & 5.0 & .4 & .0 \\
\hline & \multirow{2}{*}{$\begin{array}{c}\text { Peer- } \\
\text { Mediated }\end{array}$} & Peer Tutors & 11.6 & 2.5 & 4.6 & 3.5 & 0 \\
\hline & & APE teacher & 1.7 & .0 & 3.8 & .0 & .0 \\
\hline \multirow{4}{*}{ Laura } & \multirow{2}{*}{$\begin{array}{l}\text { Teacher- } \\
\text { Directed }\end{array}$} & Peer Tutors & 1.2 & .3 & .3 & .0 & .0 \\
\hline & & APE teacher & 22.5 & 2.5 & 6.1 & 1.6 & 1.1 \\
\hline & \multirow{2}{*}{$\begin{array}{c}\text { Peer- } \\
\text { Mediated }\end{array}$} & Peer Tutors & 32.5 & 4.6 & 8.4 & 3.4 & 6.8 \\
\hline & & APE teacher & 13.9 & 1.0 & 4.6 & .7 & 3.6 \\
\hline \multirow{4}{*}{ Mary } & \multirow{2}{*}{$\begin{array}{l}\text { Teacher- } \\
\text { Directed }\end{array}$} & Peer Tutors & 2.7 & .4 & .7 & .0 & .5 \\
\hline & & APE teacher & 11.6 & 1.6 & 6.9 & .5 & 2.7 \\
\hline & \multirow{2}{*}{$\begin{array}{c}\text { Peer- } \\
\text { Mediated }\end{array}$} & Peer Tutors & 12.9 & 8.7 & 6.5 & 2.5 & 4.6 \\
\hline & & APE teacher & 2.1 & .0 & 2.9 & .0 & .4 \\
\hline
\end{tabular}

Note: $\mathrm{P}=$ Prompt $, \mathrm{C}=\mathrm{Cue}, \mathrm{Fg}=$ Feedback General, Fs $=$ Feedback Specific, Fc $=$ Feedback Corrective

\section{Statistical Results}

Correlations were calculated between instructional, physical interaction scores of peer tutors and teachers, and activity engagement scores of target students. The activity data were significantly positively correlated with instructional data of peer tutors for Laura $(\rho=.78, p<.05)$ and for Eric $(\rho=.74, p<.05)$. Furthermore, data revealed that Laura's and Mary's peer tutors used significantly more instructions during peermediated intervention than teachers during baseline $(\mathrm{p}<.05$, Mann-Whitney $U$ test $)$. The comparison of physical interaction scores between peer tutors and teachers did not show significant differences across baseline and 
intervention phases in any of the three research sites. Finally, the significant increase was found in activity engagement scores across baseline and intervention for Laura $(p<.05$, Wilxocon test) and for Mary $(\mathrm{p}<.05$, Wilcoxon test).

\section{DISCUSSION}

Results of this study provide helpful information for APE teachers of elementary age students with SMD who may consider using peer tutoring program during inclusive GPE class. Teachers continuously are looking for efficient ways to include students with disability in a successful and meaningful way. Peer-mediated instructional accommodations may be a feasible mean of providing age appropriate and frequent instructions during GPE class for students with SMD. In addition, special education literature has showed evidence that peer tutoring can promote positive attitudes in students without disabilities towards students with disabilities (e.g., Collins, Branson, \& Hall, 1995; Hughes, Rung, Wehmeyer, Agran, Copeland, \& Hwang, 2000; Staub \& Hunt, 1993). Moreover, study by Miracle, Collins, Schuster and GrishamBrown (2001) determined that peer-delivered instructions were effective in improving the academic outcome of secondary students with moderate and severe disabilities.

In this study a peer-mediated instructional accommodation was implemented for three students with SMD in three different research sites. The findings indicated that: (a) in two research sites students with SMD (i.e., Laura and Mary) showed significantly higher activity engagement during peer-mediated instructional conditions than during APE teacher-directed conditions; (b) also, in these two sites peer tutors had significantly higher levels of instructions provided towards students with SMD during peer tutoring than teachers during teacher-directed conditions; (c) finally, in all of the three research sites peer tutors had comparable levels of activity engagement with their tutees as teachers during baseline, or teacher-directed conditions. These findings replicate positive outcomes of other studies using peer support programs in GPE class (Houston-Wilson et al., 1997; Lieberman et al., 1997, 2000). More specifically, the current study indicated that the instructional involvement of peer tutors within peermediated accommodations is an important influence on the increased activity engagement time of students with SMD.

It is important to emphasize that all peer tutors applied teaching instructions in particular order they learned during training sessions (TIP-TAP steps). Peer tutoring procedures tended to be successful and meaningful with tutors instructing, assisting and praising their tutees, while students with SMD accepted these instructions and engaged in GPE activities together with tutors. In addition, several researchers (e.g., Block et al., 2006; Greenwood \& Todd, 1988; Slininger et al., 2000) have emphasized the importance of peer involvement as a necessary part of behavioral interaction intervention because peers provide the natural contexts for targeted interaction behaviors. In addition, the organizational arrangement including systematic peer tutor rotation (i.e., $2 \times 10$ minutes) provided by the researcher could have been a reason for maintenance of a high level of interactions between peer tutors and students with SMD.

The anecdotal notes obtained throughout the study showed that during the early intervention phases APE teachers prompted tutors and showed how to assist students with SMD. As peer tutoring sessions progressed and tutors mastered their skills, teachers' involvement decreased. This study supported special education research by Odom and colleagues (1992) suggesting to use of teachers prompts and reinforcement at the beginning of the peer support intervention, while later gradually withdraw the teachers' involvement. In this study, teachers monitored the peer tutoring process and gave positive reinforcement, or specific feedback for observed students' interactions to encourage positive relationships between peer tutors and their tutees. While several sources in special education have cited adult involvement in peer support programs for students with severe 
disabilities (e.g., Cole, 1988; Cushing et al., 1997; Miracle et al., 2001; Shukla et al., 1998), similar research in inclusive GPE settings remains limited.

In terms of efficiency, two out of the three participants increased activity engagement during peer-mediated conditions. Moreover, the physical interaction scores, or activity engagement with students with SMD was similar between peer tutors during intervention and teachers during baseline phases across the three research sites. These data indicates that while activity engagement together with students with SMD did not differ between peer tutors and APE teachers, peer tutors tended to provide more frequent instructions as teachers did. Several studies in special education have indicated importance of the frequent prompt delivery strategies to foster a higher level of on-task behavior and correct task responding in persons with severe and multiple disabilities (e.g., Lancioni, Dijkstra, O'Reilly, Groeneweg \& van den Hof, 2000; Lancioni, Dijkstra, O'Reilly, Brower, Groeneweg, Bikker, Flameling, \& van den Hof, 2001; Weiner, 2005). Unfortunately, in APE research investigations addressing prompt frequency to change behaviors of students with SMD has been minimal.

Findings of this study extend previous research by Klavina and Block (2008) demonstrating importance of teaching instructions provided by tutors in increasing activity engagement time of students with SMD. Also, it is possible to further interpret our results as suggesting that peer-mediated instructional accommodations can provide multiple benefits to those involved such as (a) increased interaction behaviors between students with SMD and their peers without disabilities, (b) increased academic outcome, (c) decreased dependence on adults for students with SMD, and (d) increased positive feelings for students with SMD through experiencing sense of belonging and companionship with other classmates in GPE.

\section{Limitations}

In considering results of this study, the design may be considered as limitation in that collecting data of teachers and peer tutors across baseline and intervention phases. The instructions provided by teachers reflected the traditional instructional procedures they used when assisting particular students with SMD in GPE class, while peer tutors used TIP-TAP steps containing specific order for teaching instructions, assistance and feedback. However, the teachers noted anecdotally that TIP-TAP steps were similar to the support procedures they used to apply in APE sessions. While this does not control for possibility that the students with SMD may have responded differently if teachers also had used TIP-TAP steps as indicated in the Peer Tutor Training Manual, holding the procedure constant across the two conditions would be suggested for future studies.

Another limitation in instructions delivered by teachers and peer tutors that needs to be considered is the consistency of teaching instructions. The academic outcomes as well as the interactions between peer tutors, or teachers and students with SMD might be different if a specific prompt system, for example, constant time delayed or simultaneous prompting would be assigned.

Also, this study was limited in the data of determining the maintenance and generalization effects of peer tutoring instructional accommodations. The outcomes of the study utilizing peer tutoring across different GPE sport units and learning stages in prolonged time periods might have been different.

The purposive sample selection of participants (students with SMD, peer tutors) is another limitation. Individual characteristics of both peer tutors (e.g., previous experience in interactions with peers with disabilities) and tutees (e.g., health condition, functional capabilities, communication means), could influence the interaction measures between students with and without disabilities in this particular study.

\section{Implications for Future Research}

This study demonstrated the academic improvements observed for students with SMD 
involved in peer-mediated instructional support during GPE class. These results recommended that the role of peer tutor instructional assistance monitored and supervised by the teacher may be more influential than previously acknowledged peer support programs. While it might be assumed that adult involvement is an influential variable impacting students' performances in peer tutoring procedures, the additional and more explicit measures of teachers' involvement is needed. Future research could include (a) assessment of teachers' involvement in peer tutoring interventions, particularly, with students with SMD, (b) adjustment of teachers' involvement to academic needs of both students with and without disabilities, and (c) investigation of relationships between the academic achievements and interaction behaviors for students with and without SMD as the result of peer tutoring interventions.

\section{REFERENCES}

Allport, G. W. (1954/1979). The nature of prejudice. Cambridge, MA: Perseus Books.

Bandura, A. (1977). Social Learning Theory. New York: General Learning Press.

Block, M. E., Conatser, P., Montgomery, R., Flynn, L., Munson, D., \& Dease, R. (2001). Effects of mid school-aged partners on the motor and affective behaviors of children with severe disabilities. Palaestra, 17 (4), 34-39.

Block, M. E., Hornbaker, J. L., \& Klavina, A. (2006). The Functional Assessment for Students with Severe Disabilities. Palaestra, 22 (4), 25-31.

Block, M., Klavina, A., \& Flint, W. (2007). Including Students with Severe, Multiple Disabilities in General Physical Education. JOPERD, 78 (3), 29-32.

Cohen, J. (1960). A coefficient of agreement for nominal scales. Educational and Psychological Measurement, 20, 37-46.

Cole, D. A.(1988). Difficulties in relationships between nonhandicapped and severe mentally retarded children: The effect of physical impairments. Research in Developmental Disabilities, 9, 55-72.
Collins, B. C., Branson, T. A., \& Hall, M. (1995). Teaching generalized reading words of cooking product labels to adolescents with mental disabilities through the use of key words taught by peer tutors. Education and Training in Mental Retardation and Developmental Disabilities, 30, 65-75.

Cushing, L. S., \& Kennedy, C. H. (1997). Academic effects of providing peer support in general education classrooms on students without disabilities. Journal of Applied behavior Analyses, 30, 139-151.

DePaepe, J. L. (1985). The influence of three least restrictive environments on the content of motor - ALT, and performance of moderately mentally retarded children. Journal of Teaching in Physical Education, $5,34-41$.

Greenwood, C. R., Dinwiddie, G., Terry, B., Wade, L., Stanley, S.O., Thibadeau, S., \& Delquadri, J.C. (1984). Teacher- versus peermediated instruction: an echobehavioral analysis of achievement outcomes. Journal of Applied Behavioral Analyses, 17, 521-538.

Greenwood, C. R., \& Todd, N. M. (1988). The frequency interaction recording system: FIRS. In. Hersen, M. \& Bellack, A.S. (Eds.), Dictionary of behavioral assessment techniques (pp. 228-230). New York: Pergamon.

Houston-Wilson, C., Dunn, J. M., Van der Mars, H., \& McCubbin, J. (1997). The effect of peer tutors on motor performance in integrated physical education classes. Adapted Physical Activity Quarterly, 14, 298-313.

Kamps, D., Locke, P., Delquardri, J., \& Hall., R.V. (1989). Increasing academic skill of students with autism using fifth grade peers as tutors. Education and Treatment of Children, 12, 38-51.

Kazdin, A. E. (1982). Single case research design: Methods for clinical and applied settings. New York: Oxford University Press.

Kelly, L. E., \& Gansneder, B. (1998). Preparation and job demographics of adapted physical educators in the United States. Adapted Physical Activity Quarterly, 15, 141-154. 
Klavina, A. (2007). The Effect of Peer Tutoring on Interaction Behaviors in Inclusive Physical Education. Unpublished doctoral dissertation. University of Virginia.

Klavina, A., \& Block, E. M. (2008). The effect of peer tutoring on interaction behaviors in inclusive physical education. Adapted Physical Activity Quarterly, 25, 132-158.

Klavina, A., \& Selavo, L. (2006). Analyses of Instructional, Social and Physical Interaction in Physical Education (AISPI-PE). In J. Wittmanová (Ed.), Proceedings European Conference in Adapted Physical Activity, September 7-9, 2006 (p. 49).Olomouc: Palacký University.

Kohler, F. W., \& Strain, S. P. (1991). Maximizing peer-mediated resources in integrated preschool classrooms. Topics in Early Childhood Special Education, 19, 92102.

LaMaster, K., Gall, K., Kinchin, G., \& Seidentop, D. (1998). Inclusion practices of effective elementary specialists. Adapted Physical Activity Quarterly, 15, 64-81.

Lancioni, G. E., Dijkstra, A. W., O'Reilly, M. F., Brower, V., Groeneweg, J., Bikker, B., Flameling T., \& van den Hof, E. (2001). Frequent versus non-frequent prompts and task performance in persons with severe intellectual disabilities. Scandinavian Journal of Behaviour Therapy, 30 (3), 134-139.

Lancioni, G. E., Dijkstra, A. W., O'Reilly, M. F., Groeneweg, J., \& Van den Hof, E. (2000). Frequent versus nonfrequent verbal prompts delivered unobtrusively: Their impact on the task performance of adults with intellectual disability. Education and Training in Mental Retardation and Developmental Disabilities, 35(4), 428-433.

Lieberman, L. J., Newcomer, J., McCubbin, J., \& Dalrymple, N. (1997). The effects of cross age tutors on the academic learning time in physical education of children with disabilities in inclusive elementary physical education classes. Brazilian Journal of Adapted Physical Education \& Recreation, 4, 15-32.

Lieberman, L. J., Dunn, J. M., Mars, H., \& McCubbin, J. (2000). Peer tutors' on activity levels of deaf children in inclusive elementary physical education. Adapted Physical Activity Quarterly, 17, 20-39.

Martella, R. C., Marchand-Martella, N. E., Young, K. R., \& Macfarlane, C. A. (1995). Determining the collateral effects of peer tutor training on a child with severe disabilities. Behavior Modifications, 19 (2), 170-191.

Miracle, S. A., Collins, B. C., Schuster, J. W., \& Grisham-Brown, J. (2001). Peer - versus teacher delivered instruction: Effects on Acquisition and Maintenance. Education and Training in Mental Retardation and Developmental Disabilities, 36, 373-385.

Murata, N.M., \& Jansma, P. (1997). Influence of support personnel on students with and without disabilities in general physical education. Clinical Kinesiology, 51 (2), 3746.

Odom, S. L., Chandler, L. K., Ostrosky, M., McConnell, S. R., \& Reaney, S. (1992). Fading teacher prompts from peer-initiation interventions for young children with disabilities. Journal of Applied behavior Analyses, 25, 307-317.

Schnorr, R.F. (1997). From enrolment to membership: "Belonging" in middle and high school classes. Journal of the Association of Persons with Severe Handicaps, 22, 1-15.

Shukla, S., Kennedy, C., \& Cushing, L. S. (1998). Adult influence on the participation of peers without disabilities in peer support programs. Journal of Behavioral Education, 8 (4), 397-413.

Slininger, D., Sherrill, C., \& Jankowski, C. M. (2000). Children's attitudes towards classmates with sever disabilities: Revisiting contact theory. Adapted Physical Activity Quarterly, 17, 176-196.

Webster, G. E. (1987). Influence of peer tutors upon Academic Learning Time - Physical Education of mentally handicapped children. Adapted Physical Activity Quarterly, 6, 393403.

Weiner, J. S. (2005). Peer-mediated conversational repair in students with moderate and severe disabilities. Research and Practice for Persons with Severe Disabilities, 30(1), 26-37. 
Zhang, J., Kelly, L., Berkey, D., Joseph, D., \& Chen, S. (2000). The prevalence-based need for adapted physical education teachers in the United States. Adapted Physical Activity Quarterly, 17, 297-309.

Corresponding author's e-mail address: aija.klavina@gmail.com

\title{
KOLLEGIALE LEHR- UND LERNUNTERSTÜTZUNG (PEER MEDIATED INSTRUCTION) FÜR SCHÜLER/INNEN MIT SCHWERER UND MEHRFACH-BEHINDERUNG IM INKLUSIVEN BEWEGUNGSUNTERRICHT: FALLSTUDIEN
}

\author{
(Resümee)
}

Die Absicht dieser Studie war es, die Effektivität von kollegial unterstützten und lehrerzentrierten Lehranweisungen auf die aktive Teilnahme von Schüler/innen mit schwerer und Mehrfachbehinderung (SMB) zu ermitteln. Die Datenerhebung erfolgte während regulärer inklusiver Sportunterrichtseinheiten unter zwei Arten der Unterrichtsunterstützung für drei Schüler/innen mit SMB: (a) lehrerzentriert und (b) kollegial unterstützt (peer mediated). Die Aufzeichnungen über das Anleitungsverhalten zeigten, dass unter ,peer mediated“-Bedingungen die Anweisungen von den Tutoren häufiger waren als diejenigen der Lehrenden unter lehrerzentrierten Bedingungen. Die Daten über das Bewegungsverhalten zeigten, dass es unter ,peer mediated“-Bedingungen $\mathrm{zu}$ einem ähnlichen Niveau an Bewegungsverhalten aller drei Schüler/innen mit SMB kam wie unter lehrerzentrierten Anweisungsbedingungen. Außerdem ergab sich eine längere Aktivitätszeit für die behinderten Schüler/innen, wenn Peer -Tutors dabei waren.

SCHLÜSSELWÖRTER: Peer Tutoring, Schüler/innen mit schwerer und Mehrfachbehinderung, Adapted Physical Education

\section{L'UTILISATION DE LA MEDIATION PAR LES PAIRS DANS LES INSTRUCTIONS DONNEES A DES ELEVES EN SITUATION DE HANDICAP SEVERE EN COURS D'EDUCATION PHYSIQUE INCLUSIVE : UNE ETUDE DE CAS MULTIPLES}

(Résumé)

Le but de cette étude est de déterminer l'effet de la médiation par les pairs ou le professeur - les instructions sont données pendant le temps d'activité des élèves en situation de handicap sévère. Les données sont récoltées pendant les séances d'éducation physique inclusive. Deux situations sont expérimentées : (a) direction du professeur et (b) médiation par les pairs. Les données concernant les conduites éducatives démontrent que pendant la médiation par les pairs les consignes fournies par les tuteurs sont plus fréquentes qu'en situation dirigée par le professeur. Les données concernant les comportements propres à la pratique physique indiquent que le niveau physique atteint par tous les élèves en situation de handicap est similaire dans des conditions de médiation par les pairs ou par le professeur. De plus, pour tous les élèves en situation de handicap, le temps d'engagement est supérieur lorsque des tuteurs pairs sont impliqués.

MOTS CLEFS: Tutorat effectué par des Pairs, Elèves en Situation de Handicap, Education Physique Adaptée. 